Send your letters to the Editor,

British Dental Journal,

64 Wimpole Street

London

W1G 8YS

Email bdj@bda.org

Priority will be given to letters less than 500 words long.

Authors must sign the letter, which

may be edited for reasons of space.

\section{LOG-ON AND VOTE}

Sir, I would like to draw your attention to an exciting new website that has been set up by the Shirley Glasstone Hughes Trust Fund for dental practitioners and dental care professionals (DCPs).

The website (www.dentistryresearch. org) is an enhanced version of the online discussion forum launched last May by the Trust, and I really feel it will be of much interest to your readers.

The Primary Care Dentistry Research Forum has been developed solely for the use of dental practitioners and dental care professionals. As a small funding body for dental research, the Trust is very interested in finding out just what are the burning issues that practitioners and professionals come across in their day-to-day practice which they would like to see answered once and for all.

The new website encourages practitioners and DCPs to join the site and vote on which questions they would like to see answered with conclusive research. The new voting system will allow registered users to vote on questions and submit their own questions over a period of one month. The 'question of the month' as voted for by the members of the site will be put forward for a rapid critical review. Each month new questions will be added to the site to be voted on from data collected via the BDA's Omnibus survey. The aim is very much to encourage members of the site to think of their own questions and submit them to be included in the vote.

The Primary Care Dentistry Research Forum now also has a new Blog section where we shall publish the conclusions of the rapid critical reviews and fresh content will be added on a regular basis. The enhanced site is now much more user friendly, and the process of joining and voting takes only a moment.

We think that your readers will be very keen to join the new website and have their say on what areas of research they would like to see funded.

We would like as many practitioners and professionals as possible to log-on and get voting. It's time that they had their say on the future of primary dental care research.

E. Kay

Chair of the Shirley Glasstone Hughes Board of Trustees DOI: 10.1038/sj.bdj.2009.718

Ed's note: Readers can also find more information on pages 183-184.

\section{DPF CHANGES}

Sir, Kawaja and Renton, in their excellent recent paper, advocated the use of high-dose non-steroidal anti-inflammatory drugs combined with steroids as an adjunct to the management of implant associated inferior nerve injury. ${ }^{1}$ They drew attention to the well-recognised risk of upper gastro-intestinal ulceration, noting that the combination of steroid and NSAID is particularly likely to produce complications.

NSAIDs are widely used in dental practice and have been associated with severe complications. ${ }^{2}$ Those available in the DPF include aspirin, ibuprofen and diclofenac. ${ }^{3}$ The BNF notes that ibuprofen has the best safety profile of all NSAIDs but is considered to be less effective than other drugs.

The use of $\mathrm{H} 2$ receptor antagonists or proton pump inhibitor drugs is well documented for the protection of upper GI ulceration in patients taking NSAIDs. ${ }^{3}$ The BNF contains full details of the indications for prescription.
I would like to draw readers' attention to recent changes in the DPF, notably the availability of omeprazole and lansoprazole, for prescription on NHS Form FP10.

As these changes are new, they are not in the current paper copy of the DPF. I would recommend that those interested should log on to www.bnf.org and register; it is free and takes seconds. There are full details listed of deletions, notably pethidine, and several relevant additions including co-amoxiclav (Augmentin).

As general dental practitioners in the NHS only receive updated BNFs on a two-yearly basis, these important changes may not be appreciated if a hard copy is the only source of reference.

R. Bate Warwick

1. Khawaja N, Renton T. Case studies on implant removal influencing the resolution of inferior alveolar nerve injury. Br Dent J 2009; 206: 365-370.

2. Milner N, Dickenson A, Thomas A. The use of NSAIDs in dentistry: a case study of gastrointestinal complications. Dent Update 2006; 33: 487-490.

3. BNF 57. www.bnf.org

DOI: 10.1038/sj.bdj.2009.719

\section{MISLEADING}

Sir, I feel that the news item 'No evidence for extracting baby canine teeth' ( $B D J$ 2009; 206: 454) gives a misleading representation of a procedure which several orthodontic studies suggest is helpful.

Apart from Ericson and Kurol's ${ }^{1}$ study (to which Nicola Parkin refers without giving the reference) there have been a number of studies, including our own, Power and Short, ${ }^{2}$ which have indicated that this is a useful procedure. However, these have been discounted completely in her Cochrane Review ${ }^{3}$ for not meeting the protocol of randomised controlled 
trials (RCT), which all would agree is the gold standard for clinical trials.

Most orthodontists would concur that the removal of any deciduous teeth is only undertaken if it is felt to benefit the long term occlusal development in a child, providing the child is not likely to be unduly upset by the experience. The age for the removal of maxillary deciduous canines in cases where it is felt it would be of benefit in normalising the eruptive pathway of palatally displaced permanent canines is between 10-13 years of age and not, as implied by the accompanying photograph, in infants.

Many parents and orthodontists would feel that a simple interceptive procedure undertaken under local anaesthetic, where the palatal canine is associated with favourable features for improvement (as mentioned in our paper) is preferable to supervised inactivity leading to an established palatally impacted canine. The subsequent need for surgical exposure and general anaesthesia (GA) which is then required for many patients is much more stressful. Furthermore this latter procedure is significantly costlier to the NHS in terms of surgery and the associated longer, comprehensive course of orthodontic treatment needed.

Although isolated case reports are limited in their evidential validity the case below is of interest. After initial consultation, in which a diagnosis of palatally impacted canines was made, I requested the patient's GDP to extract both maxillary deciduous canines. Unfortunately after having the upper left deciduous canine removed the patient cancelled the appointment for the removal of the right deciduous canine; she also missed a six monthly review appointment and so was not reassessed until a year after her initial consultation. As the follow up OPT (Fig. 1) shows, the left canine assumed a normal path of eruption and aligned into position whereas the right canine continued to deteriorate with the deciduous canine still present and showing little further resorption.

Needless to say the patient's mother regretted not organising the extraction of the right deciduous canine as her child might then have been able to avoid the
GA exposure and orthodontic traction of the right permanent canine which was then required to align it.

In an ideal world I agree that the type of RCT study suggested by Dr Parkin should be undertaken and would suggest that a dental teaching hospital is the best place to do this. However, we feel here in a district general hospital any procedures which might reduce the need for costlier and longer courses of treatment requiring dento-alveolar surgery and GA is, from our ethical point of view, difficult to withhold from patients.

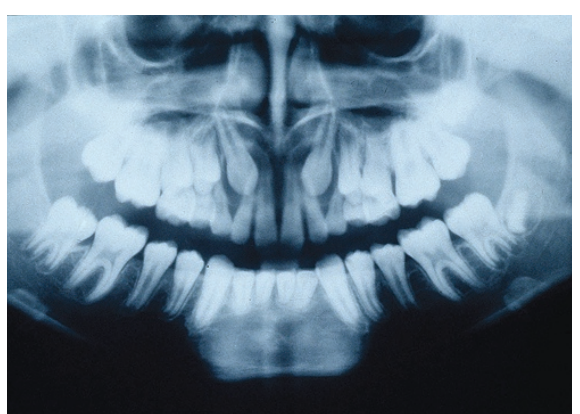

Fig. 1 Initial OPT

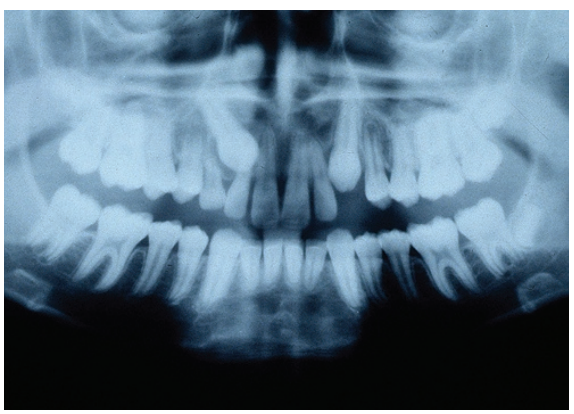

Fig. 2 Follow up OPT one year later

M. B. E. Short Bournemouth

1. Ericson S, Kurol J. Early treatment of palatally erupting maxillary canines by extraction of primary canines. Eur J Orthod 1988; 10: 283-295. 2. Power S M, Short M B. An investigation into the response of palatally displaced canines to the removal of deciduous canines and an assessment of factors contributing to favourable eruption. Br J Orthod 1993; 20: 215-223.

3. Parkin N, Benson P E, Shah A et al. Cochrane Database Syst Rev 2009; 2 .

DOI: $10.1038 /$ sj.bdj.2009.720

\section{HTM 01-05 REVISION}

Sir, given that much of the newly released Cross-Infection Control Directives HTM 01-05 has been driven by the 'theoretical' risks of prion transmission in dentistry, I am amazed that no mention has been made into products that have been proven to deactivate prions, ${ }^{1}$ rather than just removal techniques to try and eliminate proteins, where prions are tightly bound.

I am also disappointed that where HTM 01-05 states best practice, many impositions are either not evidencebased or even increase risks of transmission of disease, rather than reduce them. A good example of this is the use of unreliable and complex washer-disinfectors that finish with a high temperature rinse. It is well documented that proteins start to coagulate significantly above $40^{\circ} \mathrm{C}$ and the higher the temperature, the more stubbornly these proteins coagulate and harden on to surfaces, making their removal more difficult or impossible. ${ }^{2}$

HTM 01-05 is moving dentistry towards hospital-style sterilisation processes, which use washer-disinfectors and autoclaves routinely in central sterilisation facilities, yet scientific studies clearly show these methods leave significant levels of protein deposits on surgical instruments that are wrapped/processed and ready to use on patients. ${ }^{3}$ Printouts of completed cycles from equipment such as this may please bureaucrats but only prove that there was ink in the printer. Clinically leaving proteins that may bind active prions is worse. Surely this alone is an evidence-based reason to NOT follow HTM 01-05 to the letter in this respect, never mind enthusiastically labelling it 'best practice'?

I would suggest if any washer or washer-disinfectors are used as a preautoclave cleaning stage, the hot cycle is turned off. This will allow removal of any gross physical contamination and should inspection afterwards show minute protein deposits, these can still be further processed to allow removal, which otherwise may be impossible if proteins have been super-heated and super-coagulated on to instruments. Why should dentistry copy previously flawed methods? ${ }^{4}$

I would also suggest it is best practice to use a proven material that deactivates prions to a level that prevents transmissibility of disease. I find this most effective as a pre-cleaning soak and/or processing instruments with Prionzyme $^{\mathrm{TM}}$ in a heated ultrasonic bath. 
I am concerned that if practitioners do a proper risk assessment and evaluation of the current evidence, find that acting in the patients' best interests means they may be in conflict with recently released and compromised 'directives', which are rules that must be followed, that this brings us (unnecessarily) into conflict with our GDC professional standards. I therefore ask that HTM 01-05 be revised as soon as possible, but appreciate this still may not happen 'administratively' for some time. Perhaps now that the BDA have produced their new A12 Guidance online, this is the document the dental profession should refer to for any latest developments or new evidence for cross infection control. Updating our profession in an evidence based way and in a timely manner is critical. I am concerned that HTM 01-05 directives could be slow or even obstructive to amendment by comparison.

\section{T. Kilcoyne By email}

1. McLeod A H, Murdoch H, Dickinson J, Dennis M J et al. Proteolytic inactivation of the bovine spongiform encephalopathy agent. Biochem Biophys Res Commun 2004; 317: 1165-1170.

2. Opinion of the Scientific Committee on Vetinary Measures relating to Public Health. The Cleaning and Disinfection of Knives in the Meat and Poultry Industry. Para 6.3, p 17. June 2001.

3. Murdoch H, Taylor D, Dickinson J, Walker J T et al. Surface decontamination of surgical instruments: an ongoing dilemma. J Hosp Infect 2006; 63: 432-438.

4. Palacios-Sánchez B, Esparza-Gómez G C Campo-Trapero J, Cerero-Lapiedra R. Implications of prion diseases for dentistry: an update. Oral Surg Oral Med Oral Pathol Oral Radiol Endod 2008; 105: 316-320.

DOI: 10.1038/sj.bdj.2009.721

\section{DRAGGING ITS FEET}

Sir, I write in response to a letter from T. Lynn (BDJ 2009; 206: 508-509; HIV rules) and to support, from personal experience, the points made.

It is current UK policy to commence antiretroviral treatment (HAART) when the CD4 (white T-cell) count of an HIV infected individual falls below 350. The count rises rapidly again with effective HAART and the viral load eventually becomes undetectable (to be precise, less than 50 viral particles per unit volume). Normal CD4 counts are somewhat in the range $600-1,000$ or more. It does not mean the patient is cured but his/her infectivity is very significantly reduced. T. Lynn asks if it is not time to change the rules.
I have personally battled since 2005 to effect that change, writing to the Secretary of State and his junior ministers, all of whom produced the same standard answer that it is 'being reviewed'. A classic case of passing the buck. I have tried my local MP and had huge support from the BDA but there has been no change. The United Kingdom Advisory Panel (UKAP) still insists that its policy is correct and that all the other countries have got it wrong.

With the help of the BDA and its editorial staff I was able to bring to the attention the iniquitous situation which currently exists for HIV +ve dentists. ${ }^{1}$ How is it that a dentist may not refuse to treat or show any special treatment discriminations to any HIV +ve patient without risk of being hauled before the GDC for professional misconduct, but an HIV +ve dentist may not touch any patient at all?

The consequence is that no dentist newly diagnosed with HIV is ever going to give him/herself up to the public health authorities as I did because the ground will be ripped out from under them. I don't blame them for one second. By exposing the facts I feel I blew UKAP's policy out of the water. To my knowledge, despite all these HCWs who are HIV +ve furtively continuing to work, there is still no evidence worldwide of a dentist transmitting HIV to a patient (save the disputed David Acer case in Florida in 1989).

T. Lynn believes that HIV infected dentists among other healthcare workers (HCWs) 'should avoid exposure prone procedures (EPPs)'. In fact, any HCW in the UK who practises any type of EPP is expressly banned from carrying out his or her profession by the current nearly 20-year-old policy. Although this allows for the making of full dentures, rather unfathomably, it also includes taking intra-oral radiographs. However, an HIV +ve dentist may canulate a patient for phlebotomy or anaesthetic reasons anywhere outside the mouth on the grounds that s/he can see what they are doing as opposed to giving a local anaesthetic in the mouth and risk needle stick injury to themselves while in the oral cavity.

Since there are a small number of patients requiring full dentures there is effectively no career left to these colleagues. As for teaching, what educational qualifications, CV or special expertise might the average GDP have in order to suddenly pursue a career in academia? Furthermore, once UKAP has removed the right to effectively practise they provide no support whatsoever. There is no lateral placement, no retraining and no compensation available. These dentists are quite literally thrown out on their ear. Such a dismissal in any other field would surely end up at the industrial tribunal.

While we are constantly reminded that all dentistry - indeed all clinical applications - must be evidence-based, why is it that UKAP can dictate a policy which is not?

The rapid development of antiretrovirals has turned HIV from a fatal disease to a chronic one in the UK. Individuals who may suspect they might have been exposed to the virus can now take PEP (post exposure prophylaxis) so the 'deadly' threat of HIV remains as a stigmatised, politicised and prejudiced disease.

In a paranoiac concern of some unforeseen disaster occurring, the powers that be fear for their professional reputations. The USA, Canada, Israel and I believe now China amongst several nations now allow dentists with undetectable viral loads and well treated by antiretrovirals to return to work. The UK will continue to drag its feet it seems.

Anon
HIV +ve and consequently former UK GDP

1. Anon. This was something that happened to someone else - an HIV positive dentist explains. Br Dent J 2006; 201: 697-698.

DOI: $10.1038 /$ sj.bdj.2009.722 